\title{
Some Things I Learned at the AACE/EACE/CPEN Meeting
}

\author{
Joseph O'Donnell
}

Published online: 10 November 2010

(C) Springer 2010

I came home from the AACE/EACE/CPEN Meeting with a head brimming with ideas. I must admit I couldn't tell which presentation was from a CPEN member and which was from an AACE member! I couldn't tell which were the best hula dancers at the Luau either!

We heard a nice synopsis report regarding Dr Varmus' priorities at the NCI. He wants to ramp up clinical trials. It takes too long to get from concept to accrual and more than $60 \%$ of trials have less than 6 participants. I had a nice talk with the NCI's (and our) editorial board member Rose Mary Padberg and she'll write a paper on initiatives they have at NCI on clinical trials education. Our groups and this journal can help in this arena.

Dr Varmus also wants to foster the application of personalized (he likes the term genomic) medicine. He'll be pushing for the cancer genomic atlas project. Global Health will be a big issue - that's the theme for next year's conference! I heard great presentations from the international cancer information service group (www.icsisg.org) and was amazed at their reach into so many countries. I also heard from Carolyn Messner (who constantly reminds me of the reach that telephones can have) about all of her programs at CancerCare, which are now available across the globe, and the awesome (the only word to describe it) St Jude program, Cure4kids, which brings pediatric oncology information to the world (www.Cure4Kids.org). Global research will help this country and Canada learn to deal better with ethnic minority populations (see the NCI's Office of Latin American Cancer Projects, for example). Tobacco control remains big on the NCI's screen. Another priority is stimulating the next generation of scientists, and our organizations can play a big part (the US Science and Engineering Festival was taking place on the National Mall at the same time as our meeting, and was attended by President Obama). And finally, the NCI will try to foster "comparative effectiveness research."

One special presentation of many was that of Kathy Blazer and her colleagues at City of Hope, who spoke about how their wonderful genetics education program was sprouting seeds whereever their trainees were working. Kathy used the apt business analogy "communities of practice." I think that image describes exactly what we want - widely dispersed but connected sites of excellence, pushing the mission to understand and control cancer forward! This important image depicts what we all should be and can be doing to spread and connect and use education to decrease the burden of suffering from cancer across the globe.

Read the abstracts! Presenters, send in papers! Submit something for next year's meeting in Buffalo, which will take place September 8-10, 2011. We CAN change the world by working together in effective communities of practice. Let's do it!

J. O'Donnell $(\bowtie)$

Journal of Cancer Education, Dartmouth Medical School,

Hanover, NH 03755, USA

e-mail: joseph.f.odonnell@dartmouth.edu 